\title{
Effects of mestranol on estrogen receptors expression in zebrafish
}

\author{
Lianqiang Cheng ${ }^{1}$, Xiaowen Wang ${ }^{1}$, Shijun $\mathrm{Li}^{2}$, Yongjun $\mathrm{Liu}^{3}$, Zhengxin Guo ${ }^{1, *}$ \\ ${ }^{1}$ College of Environmental Science and Engineering, Shanxi University, Shanxi, China \\ ${ }^{2}$ Department of Environmental and Resource Science, Shanxi University, Shanxi, China \\ ${ }^{3}$ Department of Chemistry and Chemical Engineering, Shanxi University, Shanxi, China
}

Corresponding to: Dr. Zhengxin Guo, Email: zhengxin.guo@mail.com; College of

Environmental Science and Engineering, Shanxi University, Shanxi, China

Short title: Mestranol regulates zebrafish ER expression

Keywords: mestranol; estrogen receptor (ER); esr1; esr2a; esr2b 


\begin{abstract}
The estrogen receptor (ER) genes, which encode a group of important ligandactivated transcriptional factors, can modulate estrogen-target gene activities. Zebrafish (Danio rerio) have three ER receptor genes, esrl, esr $2 a$, and esr $2 b$. In this study, we examined the mRNA expression levels of these ER receptors after treatment with mestranol (EE3ME). Zebrafish larvae were exposed to 0.01, 0.1, 1, and $10 \mathrm{mg} / \mathrm{L}$ from 6 hours post-fertilization (hpf) and the mRNA expression levels of the ER genes were determined at 24, 48, 72 and $96 \mathrm{hpf}$. Treatment with mestranol led to a significant stimulation of esrl mRNA expression at lower concentration and reached maximum at 72 hpf, however, the esr1 mRNA levels were reduced at higher mestranol concentration during exposure. The gene expression of esr $2 b$ was markedly decreased and the esr $2 a$ remained unaffected at all concentration in the duration. Altogether, these results suggested mestranol might cause the disruption of endocrine activities in fish by mediating ER genes expression.
\end{abstract}

\title{
Introduction
}

In all vertebrates, estrogens play important roles in many physiological processes, including general homeostasis and growth, and influence reproductive and nonreproductive target tissues [1-5]. These effects are mediated by numerous nuclear receptor proteins, the $\operatorname{ER} \alpha$ and $\operatorname{ER} \beta$, which acting as ligand-activated transcription factors regulate estrogen downstream gene expression [6-9]. In vertebrates, three isoforms of ERs, ER $\alpha, \mathrm{ER} \beta$ and $\mathrm{ER} \gamma$, have been cloned and characterized [10-12]. Estrogen activity is closely associated with endocrine disruptors and pharmaceutical 
estrogens in aquatic animals [13-16]. The disrupting chemicals cause severely endocrine dysfunctions in reproductive and developmental processes [17-21].

Mestranol, also knows as Ethynylestradiol 3-methyl ether, is a widely used synthetic steroidal estrogen [22]. Mestranol is the 3-methyl ether of ethynylestradiol, which is further converted to ethinylestradiol by demethylation in the liver [23]. The effects of estrogenic mestraol in the wildlife are largely unknown. Zebrafish (Danio rerio), a small tropical fish native to the rivers of South Asia and India [24, 25], has become one of the most important animal model in the research of developmental biology and toxicology [26-29]. Zebrafish have a wide variety of unique features including rapid development, easy maintenance, large number of offspring, transparency of embryos and access to experimental manipulation [30-32]. Many key genes and signaling pathways are highly conserved between zebrafish and advanced vertebrates [33, 34]. Due to many zebrafish lines of monogenic human genetic disease have been generated through forward genetic screens, supplying powerful tools to explore the basic cell biological processes that underlie the disease phenotype [35].

Zebrafish have three estrogen receptors, esrl, esr2a and esr $2 b[4,36,37]$. The aim of this study was to determine the changes of estrogen receptors (ER) mRNA expression levels in zebrafish larvae treated with mestranol.

\section{Materials and methods}

\section{Zebrafish husbandry}

Zebrafish were raised and maintained as described [38, 39]. Zebrafish embryos were obtained by pair-wise mating of adult fish. 


\section{Preparation of mestranol solutions}

Mestranol (Sigma-aldrich) was dissolved in dimethyl sulfoxide (DMSO) (Sigmaaldrich) to make a stock solution $(10 \mathrm{mg} / \mathrm{mL})$. For the work solutions, to dilute 0.001 , $0.01,0.1$ and $1 \mathrm{~mL}$ of stock solution into $1 \mathrm{~L}$ aquarium water to make a final concentration of $0.01,0.1,1$ and $10 \mathrm{mg} / \mathrm{L}$, respectively. Zebrafish embryos were treated with different concentration of mestranol starting at $6 \mathrm{hpf}$, and samples were collected at 24, 48, 72 and 96 hpf. The control larvae were treated with same amount of DMSO in aquarium water.

\section{RNA extraction and cDNA synthesis}

Total RNA was extracted from 50 embryos using the Direct-zol RNA MiniPrepKit (Zymo) according to the manufacturer's instruction. One microgram of RNA was digested with $10 \mathrm{U}$ DNaseI (NEB) to remove DNA contaminations for $30 \mathrm{~min}$ at $37^{\circ} \mathrm{C}$. The RNA was purified using OneStep PCR Inhibitor Removal Kit (Zymo) and the first strand cDNA was synthesized using the RevertAid First Strand cDNA Synthesis Kit (Thermo Fisher Scientific) according to the manufacturer's protocol. The cDNA samples were diluted 10 times as template in the real-time PCR assays.

\section{Real-time PCR}

Real-time PCR was performed as described somewhere else [40]. Briefly, qPCR mixture were prepared using iQ SYBR Green Supermix (Bio-Rad) and amplified using a CFX96 Touch Real-Time PCR Detection System (Bio-Rad). Primers specific for zebrafish esr1 (NM_152959.1), F-5'-GACTACGCCTCTGGATATCATTAC-3' and R- 
5' - TGGTCGCTGGACAAACATAG-3'; esr2a (NM_180966.2), F-5'-

GTCCGAGGTCTCAAGAGATAAAG-3' and R-5' -

CTTCCATGATCCGGGAGATTAG-3'; esr2b (NM_174862.3), F-5' -

CAGACAACAGAGCCCAGAAA-3' and R-5'- TCCTCTCGAAGCAGACTAGAA-3'; and $\beta$-actin (NM_131031), F-5' -TGCCCCTCGTGCTGTTTT-3' and R-5' -

TCTGTCCCATGCCAACCAT-3'. Primer specificity was confirmed by standard curve analysis and the mRNA expression of the three estrogen receptors was normalized to $\beta$ actin. Each experiment was carried out at least three times in triplicates. Calculated $\mathrm{p}$ values were considered significant at $<0.05$.

\section{Statistical analysis}

The data were analyzed using the Statistical Package for the Social Sciences (SPSS) and one-way ANOVA with Tukey's multiple comparison test was used for comparing multiple groups.

\section{Results}

\section{Effect of mestranol exposure on ER expression in zebrafish larvae}

To investigate the possible role of mestranol in zebrafish larvae, we treated the wild type embryos from $6 \mathrm{hpf}$ to different concentration of mestranol $(0,0.01,0.1,1$ and 10 $\mathrm{mg} / \mathrm{L})$. The mRNA levels of esrl were increased during the developmental stages from 24 to 96 hpf (Fig. 1A). At low concentration of mestranol (0.01 and $0.1 \mathrm{mg} / \mathrm{L})$, the embryos showed increasing esrl mRNA expression during the treatment, and reached the maximum at the $72 \mathrm{hpf}$. However, the esr 1 mRNA expression was induced at $24 \mathrm{hpf}$ but 
consistently decreased during the exposure at the concentration of $1 \mathrm{mg} / \mathrm{L}$. Higher concentration $(10 \mathrm{mg} / \mathrm{L})$ of mestranol inhibited the esrl mRNA expression compared to the non-treated controls $(0 \mathrm{mg} / \mathrm{L})$. The mRNA expression levels of esr $2 a$ were slightly increased at low concentration of mestranol exposure $(0.01-1 \mathrm{mg} / \mathrm{L})$ at the first $72 \mathrm{hpf}$ (Fig. 1B). However, the esr2a mRNA level were unchanged at higher concentration of mestranol treatment $(10 \mathrm{mg} / \mathrm{L})$ in the duration. At lower concentration $(0.01$ and 0.1 $\mathrm{mg} / \mathrm{L}$ ) of mestranol, the mRNA levels of esr2b were strongly induced during the exposure (24-96 hpf). However, higher concentration (1 and $10 \mathrm{mg} / \mathrm{L}$ ) of mestranol inhibited the esr $2 b$ mRNA expression (Fig. 1C).

\section{Discussion}

This study investigated the in vivo effects of mestranol on the ER genes expression levels in zebrafish embryos. The expression levels of all three receptors in different tissues have previously been reported [41] and here we showed expression levels of these three genes in zebrafish larvae treated with mestranol. The mRNA expression levels indicated that the response in the zebrafish embryos of esr1, esr2a and esr2b was different when exposed to various concentrations of mestranol.

Many genes have been characterized that respond to ER in presence of ligand [4246], however, only a few number of genes have been identified in fish [12, 47]. The zebrafish has become a valuable animal model for investigating synthetic ligands that could affect the endocrine system.

The existence of two esr 2 genes may due to the gene duplication in zebrafish. These two genes have different expression levels possibly because of functional differences 
between $e s r 2 a$ and $e s r 2 b$. The low esr $2 a$ gene expression levels in each group suggested that the esr2 genes might have diverse functions during embryonic development.

Treatment with lower concentration of mestranol induced expression of esr 1 and esr $2 b$

indicated that these genes were under regulatory control.

Environmental synthetic chemicals are generally considered as "weak estrogens"

which could possibly be challenged by the potency they seem to have. Mestranol has the capacity to disrupt events during development and these effects are detected at lower concentrations that have no affecting survival. Zebrafish embryos are well suited as in vivo experimental model for evaluating molecular effects that exposed to mestranol.

\section{References}

1. Kipp, M., et al., Estrogen and the development and protection of nigrostriatal dopaminergic neurons: concerted action of a multitude of signals, protective molecules, and growth factors. Frontiers in neuroendocrinology, 2006. 27(4): p. 376-390.

2. Nakamura, T.J., et al., Estrogen differentially regulates expression of Per 1 and Per2 genes between central and peripheral clocks and between reproductive and nonreproductive tissues in female rats. Journal of neuroscience research, 2005. 82(5): p. 622-630.

3. Maggi, A., et al., Estrogens in the nervous system: mechanisms and nonreproductive functions. Annu. Rev. Physiol., 2004. 66: p. 291-313.

4. Menuet, A., et al., Molecular Characterization of Three Estrogen Receptor Forms in Zebrafish: Binding Characteristics, Transactivation Properties, and Tissue Distributions 1. Biology of reproduction, 2002. 66(6): p. 1881-1892.

5. Leung, K.-C., et al., Estrogen regulation of growth hormone action. Endocrine Reviews, 2004. 25(5): p. 693-721.

6. Hall, J.M., J.F. Couse, and K.S. Korach, The multifaceted mechanisms of estradiol and estrogen receptor signaling. Journal of Biological Chemistry, 2001. 276(40): p. 36869-36872.

7. Bjornstrom, L. and M. Sjoberg, Mechanisms of estrogen receptor signaling: convergence of genomic and nongenomic actions on target genes. Molecular endocrinology, 2005. 19(4): p. 833-842. 
8. Thornton, J.W., E. Need, and D. Crews, Resurrecting the ancestral steroid receptor: ancient origin of estrogen signaling. Science, 2003. 301(5640): p. 1714-1717.

9. Matthews, J. and J. Gustafsson, Estrogen receptor and aryl hydrocarbon receptor signaling pathways. Nucl Recept Signal, 2006. 4: p. e016.

10. Halm, S., et al., Cloning, characterisation, and expression of three oestrogen receptors (ER $\alpha, E R \beta 1$ and ER $\beta 2$ ) in the European sea bass, Dicentrarchus labrax. Molecular and cellular endocrinology, 2004. 223(1): p. 63-75.

11. Hawkins, M.B., et al., Identification of a third distinct estrogen receptor and reclassification of estrogen receptors in teleosts. Proceedings of the National Academy of Sciences, 2000. 97(20): p. 10751-10756.

12. Nelson, E.R. and H.R. Habibi, Estrogen receptor function and regulation in fish and other vertebrates. General and comparative endocrinology, 2013. 192: p. 15-24.

13. Tyler, C., S. Jobling, and J. Sumpter, Endocrine disruption in wildlife: a critical review of the evidence. Critical reviews in toxicology, 1998. 28(4): p. 319-361.

14. Sumpter, J.P. and A.C. Johnson, Lessons from endocrine disruption and their application to other issues concerning trace organics in the aquatic environment. Environmental Science \& Technology, 2005. 39(12): p. 43214332.

15. Rosenfeldt, E.J. and K.G. Linden, Degradation of endocrine disrupting chemicals bisphenol A, ethinyl estradiol, and estradiol during UV photolysis and advanced oxidation processes. Environmental Science \& Technology, 2004. 38(20): p. 5476-5483.

16. Ribeiro, C., et al., Seasonal and spatial distribution of several endocrinedisrupting compounds in the Douro River Estuary, Portugal. Archives of Environmental Contamination and Toxicology, 2009.56(1): p. 1-11.

17. Markey, C.M., et al., Endocrine disruptors: from Wingspread to environmental developmental biology. The Journal of steroid biochemistry and molecular biology, 2002. 83(1): p. 235-244.

18. Sikka, S.C. and R. Wang, Endocrine disruptors and estrogenic effects on male reproductive axis. Asian journal of andrology, 2008. 10(1): p. 134-145.

19. Vos, J.G., et al., Health effects of endocrine-disrupting chemicals on wildlife, with special reference to the European situation. Critical reviews in toxicology, 2000.30(1): p. 71-133.

20. Barouki, R., et al., Developmental origins of non-communicable disease: implications for research and public health. Environmental Health, 2012. 11(1): p. 42.

21. Fisher, J.S., Environmental anti-androgens and male reproductive health: focus on phthalates and testicular dysgenesis syndrome. Reproduction, 2004. 127(3): p. 305-315.

22. Elks, J., The dictionary of drugs: chemical data: chemical data, structures and bibliographies. 2014: Springer.

23. Gillmer, M.D., Metabolic effects of combined oral. Contraception: Science and Practice, 2013: p. 11. 
24. Spence, R., et al., The behaviour and ecology of the zebrafish, Danio rerio. Biological Reviews, 2008. 83(1): p. 13-34.

25. Haffter, P., et al., The identification of genes with unique and essential functions in the development of the zebrafish, Danio rerio. Development, 1996. 123(1): p. 1-36.

26. Lele, Z. and P. Krone, The zebrafish as a model system in developmental, toxicological and transgenic research. Biotechnology advances, 1996. 14(1): p. 57-72.

27. Hill, A.J., et al., Zebrafish as a model vertebrate for investigating chemical toxicity. Toxicological sciences, 2005. 86(1): p. 6-19.

28. Teraoka, H., W. Dong, and T. Hiraga, Zebrafish as a novel experimental model for developmental toxicology. Congenital anomalies, 2003.43(2): p. 123-132.

29. Zhong, L., et al., Investigation of effect of $17 \alpha$-ethinylestradiol on vigilin expression using an isolated recombinant antibody. Aquatic toxicology, 2014. 156: p. 1-9.

30. Gu, Q. and X. Yang, Genotyping Of Zebrafish Embryos Fixed By Paraformaldehyde. bioRxiv, 2017: p. 118331.

31. Scholz, S., et al., The zebrafish embryo model in environmental risk assessment-applications beyond acute toxicity testing. Environmental Science and Pollution Research, 2008. 15(5): p. 394-404.

32. Lessman, C.A., The developing zebrafish (Danio rerio): A vertebrate model for high - throughput screening of chemical libraries. Birth Defects Research Part C: Embryo Today: Reviews, 2011. 93(3): p. 268-280.

33. Yang, X., et al., Nucleoporin 62-like protein activates canonical Wnt signaling through facilitating the nuclear import of $\beta$-catenin in zebrafish. Molecular and cellular biology, 2015. 35(7): p. 1110-1124.

34. Zhai, G., et al., Sept6 is required for ciliogenesis in Kupffer's vesicle, the pronephros, and the neural tube during early embryonic development. Molecular and cellular biology, 2014. 34(7): p. 1310-1321.

35. Gu, Q., et al., Genetic ablation of solute carrier family 7a3a leads to hepatic steatosis in zebrafish during fasting. Hepatology, 2014. 60(6): p. 1929-1941.

36. Menuet, A., et al., Analysis of the estrogen regulation of the zebrafish estrogen receptor (ER) reveals distinct effects of ERalpha, ERbeta1 and ERbeta2. Journal of Molecular Endocrinology, 2004. 32(3): p. 975-986.

37. Tingaud-Sequeira, A., et al., Expression patterns of three estrogen receptor genes during zebrafish (Danio rerio) development: evidence for high expression in neuromasts. Gene Expression Patterns, 2004. 4(5): p. 561-568.

38. Gu, Q., et al., Generation and characterization of a transgenic zebrafish expressing the reverse tetracycline transactivator. Journal of Genetics and Genomics, 2013.40(10): p. 523-531.

39. Westerfield, M., The zebrafish book: a guide for the laboratory use of zebrafish (Danio rerio). 2000: University of Oregon press.

40. Song, G., et al., Effective gene trapping mediated by Sleeping Beauty transposon. PloS one, 2012. 7(8): p. e44123. 
41. Chandrasekar, G., et al., Levels of $17 \beta$-estradiol receptors expressed in embryonic and adult zebrafish following in vivo treatment of natural or synthetic ligands. PloS one, 2010.5(3): p. e9678.

42. Anderson, D.M., et al., $A$ homologue of the TNF receptor and its ligand enhance T-cell growth and dendritic-cell function. Nature, 1997.390(6656): p. 175179.

43. Matthews, J. and J.-Å. Gustafsson, Estrogen signaling: a subtle balance between $E R \alpha$ and ER $\beta$. Molecular interventions, 2003. 3(5): p. 281.

44. Enmark, E., et al., Human estrogen receptor $\beta$-gene structure, chromosomal localization, and expression pattern 1. The Journal of Clinical Endocrinology \& Metabolism, 1997. 82(12): p. 4258-4265.

45. Zhao, C., K. Dahlman-Wright, and J. Gustafsson, Estrogen receptor beta: an overview and update. Nucl Recept Signal, 2008. 6(003).

46. Thornton, J.W., Evolution of vertebrate steroid receptors from an ancestral estrogen receptor by ligand exploitation and serial genome expansions. Proceedings of the National Academy of Sciences, 2001. 98(10): p. 56715676.

47. Cheshenko, K., et al., Expression of zebra fish aromatase cyp19a and cyp19b genes in response to the ligands of estrogen receptor and aryl hydrocarbon receptor. Toxicological sciences, 2007. 96(2): p. 255-267.

Figure 1 Effect of mestranol on esr expression levels in early-life stages. Expression levels of esr1 (A), esr2a (B) and esr2b (C) genes in early larvae treated with different concentration of mestranol. Embryos were exposed to mestranol (0.01, 0.1, 1 and 10 $\mathrm{mg} / \mathrm{L})$ or non-treated control $(0 \mathrm{mg} / \mathrm{L})$ from $6 \mathrm{hpf}$ and samples were collected at 24,48 , 72 and $96 \mathrm{hpf}$ and processed for qPCR. Transcript levels after treatment were shown. Data were represented as mean \pm SD of three independent experiments. ${ }^{*} \mathrm{p}<0.05$; $* * \mathrm{p}<0.01$ 


\section{A}

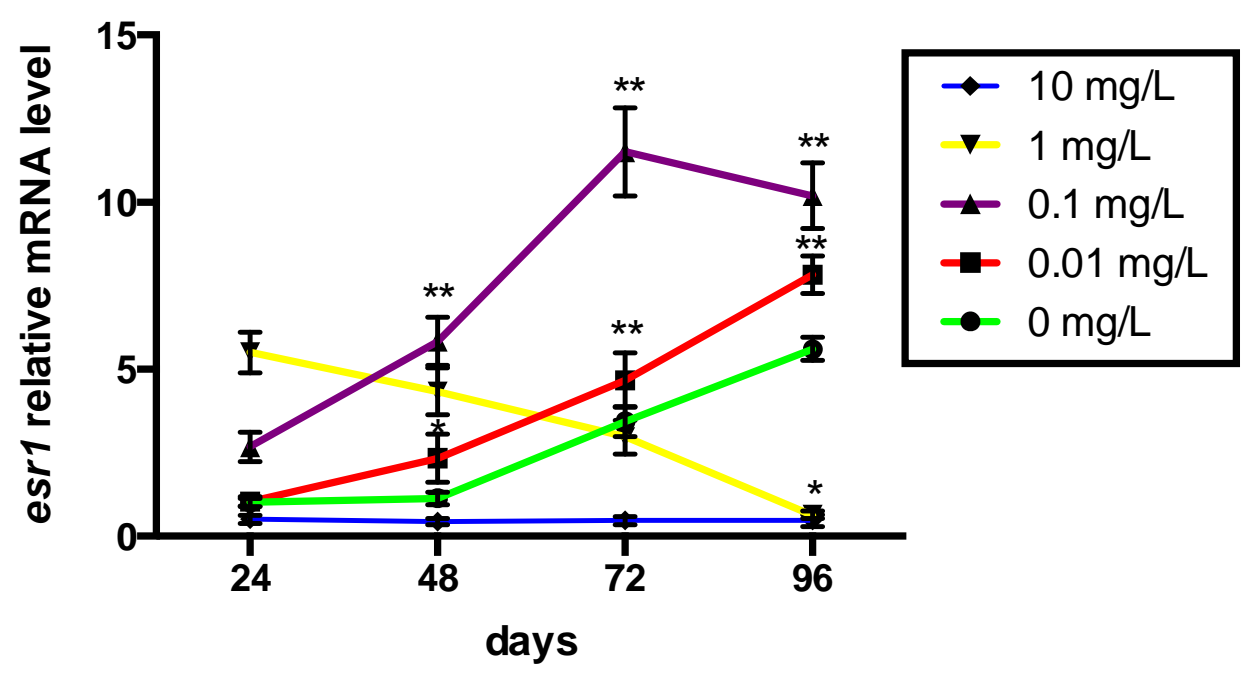

B

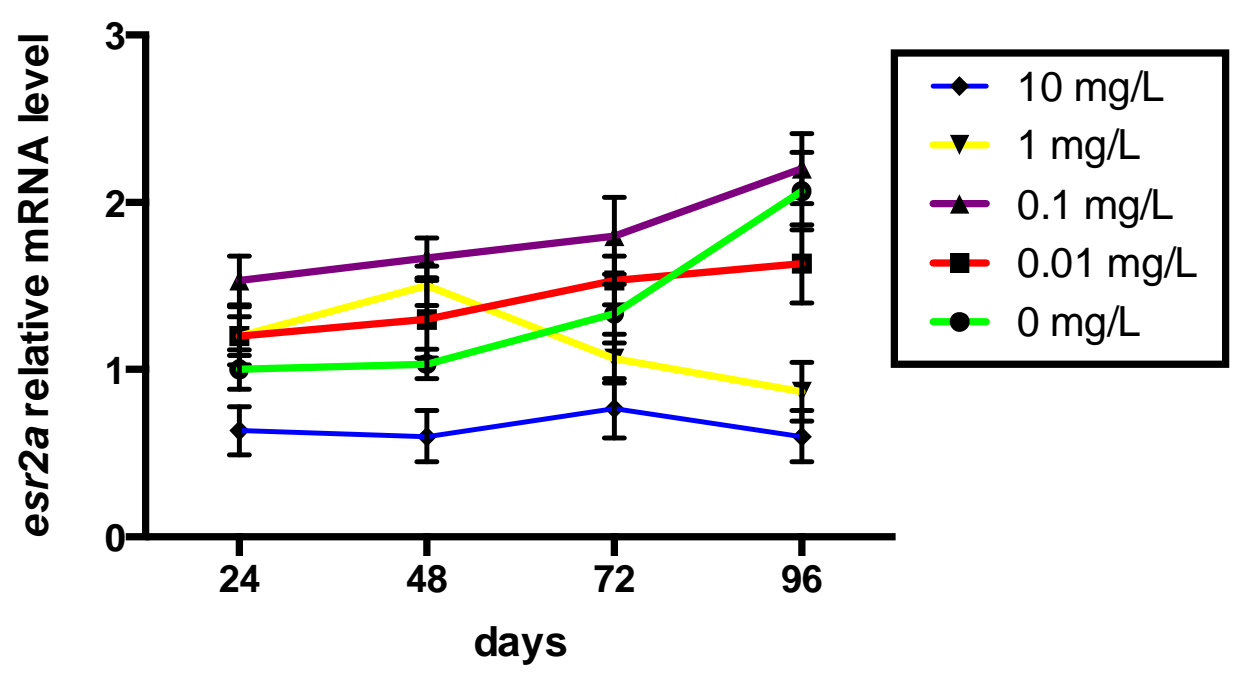


bioRxiv preprint doi: https:/doi.org/10.1101/129502. this version posted April 21 2017. The copyright holder for this preprint (which was not certified by peer review) is the author/funder, who has granted bioRxiv a license to display the preprint in perpetuity. It is made available under aCC-BY-NC-ND 4.0 International license.

\section{C}

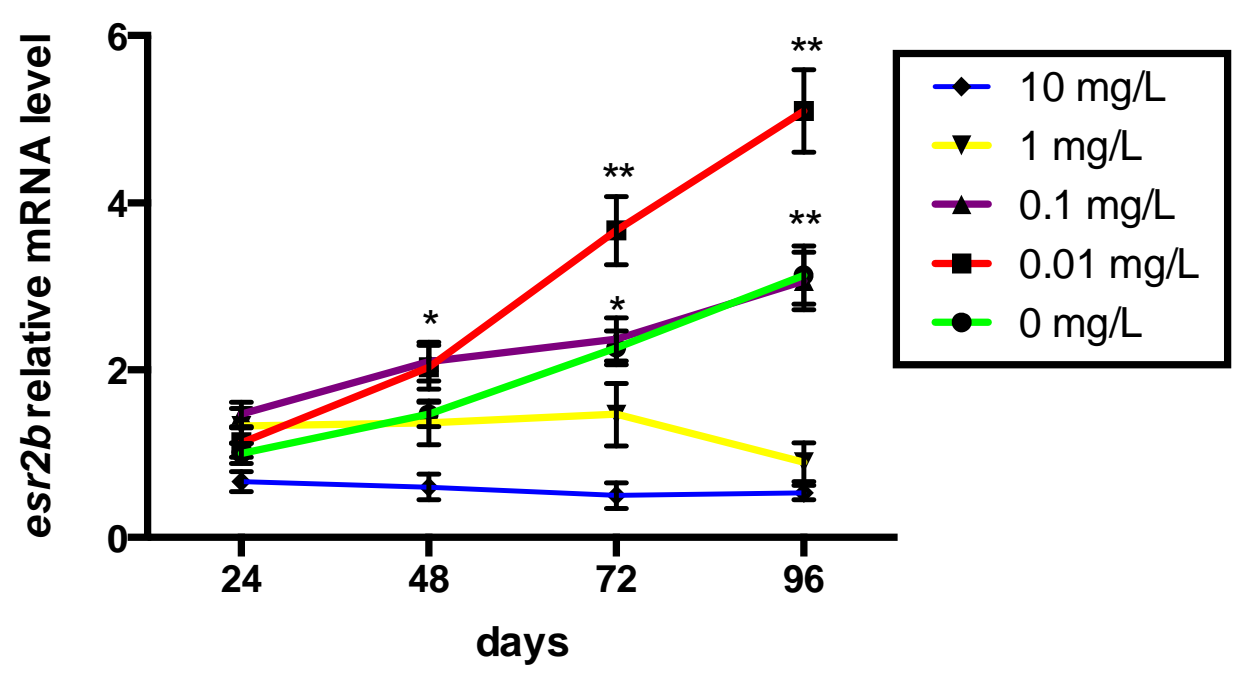

